\title{
Anxiety symptoms and quality of interaction among oncology nurses: a correlational, cross-sectional study
}

\author{
Sintomas de ansiedade e qualidade da interacção entre equipes de \\ enfermagem oncológica: um estudo correlacional e transversal \\ Los síntomas de ansiedad y la calidad de interacción entre los equipos de \\ enfermería oncológica: un estudio correlacional y transversal
}

Maria NK. Karanikola1', Margarita Giannakopoulou², Maria Kalafati², Charis P. Kaite ${ }^{1}$, Elisabeth Patiraki ${ }^{2}$, Meropi Mpouzika', Elisabeth E.D. Papathanassoglou' ${ }^{1}$, Nicos Middleton ${ }^{1}$

How to cite this article:

Karanikola MNK, Giannakopoulou M, Kalafati M, Kaite CP, Patiraki E, Mpouzika M, et al. Anxiety symptoms and quality of interaction among oncology nurses: a correlational, cross-sectional study. Rev Esc Enferm USP. 2016;50(5):800-807. DOI: http://dx.doi.org/10.1590/S0080-623420160000600013

${ }^{1}$ Cyprus University of Technology, School of Health Sciences, Department of Nursing, Limassol, Cyprus.

${ }^{2}$ University of Athens, Faculty of Nursing, Athens, Greece.

\begin{abstract}
Objective: To explore the severity of Anxiety Symptoms (AS) among Greek oncology nursing personnel, the degree of satisfaction from professional relationships, and potential association between them. Method: A descriptive cross-sectional correlational study was performed in 2 Greek Oncology Hospitals, in 72 members of nursing personnel. Hamilton Anxiety Scale was used for the assessment of AS severity and the Index of Work Satisfaction subscale "Satisfaction from Interaction" for the degree of satisfaction from professional relationships among nursing personnel (NN) and between nursing personnel and physicians (NP). Results: $11 \%$ of the sample reported clinical AS $[\geq 26$, scale range (SR): 0-52]. Satisfaction from NN [5.10 (SD: 1.04), SR: 1-7], and NP [4.21 (SD: 0.77), SR: 1-7] professional interaction were both moderate. Statistically significantly associations were observed between clinical AS and satisfaction from NN $(p=0.014)$ and NP $(p=0.013)$ professional interaction. Conclusions: Anxiety reduction interventions and improvement of professional relationships are essentials in order to reduce oncology nurses' psychological distress.
\end{abstract}

\section{DESCRIPTORS}

Anxiety; Oncology Nursing; Depression; Interprofessional Relations; Job Satisfaction; Occupational Health. 


\section{INTRODUCTION}

Anxiety symptoms (AS) are the most common manifestations of mental health problems in general population including health care professionals, such as nurses ${ }^{(1)}$. Anxiety is a maladaptive feeling of intense and indeterminate fear, followed by physical and neuro-cognitive disturbances due to Autonomic Nervous System stimuli, including not only palpitations and sweating, but sleep disturbances, phobias or depressive symptoms, as well ${ }^{(2)}$. Anxiety symptoms in the work environment may have a negative effect on employee's personal, social and professional life ${ }^{(2)}$, and may result in behavioral alterations associated with the quality of provided nursing care ${ }^{(3)}$, as well as intra-professional and inter-professional relationships ${ }^{(4)}$. Employee's satisfaction from professional interaction reflects the degree of positive feelings about formal and informal social and professional contacts within the health care job context, and subsequently an indicator of the quality of communication and collaboration between nurses and physicians, as well as among nurses ${ }^{(5)}$. However, there are scant data regarding the prevalence of AS among oncology nurses, as well as any association with the quality of interaction among oncology health profession$\mathrm{als}^{(4)}$. At the same time, research data reveal that clinicians' repetitive exposure to death, as it happens in oncology nurses since they care for dying patients and their families, makes individuals conscious of their own mortality and contributes to increased levels of death anxiety and depressive symptoms ${ }^{(6-7)}$. Death anxiety refers to reactions of phobia toward thoughts or themes related to death or dying ${ }^{(7)}$ and along with depressive symptoms, such as cognitive disturbances or irritability are mental health problems often associated with general anxiety symptoms ${ }^{(2)}$.

Understanding the degree of symptoms of mental health problems, including AS, in oncology nurses and possible determinants may help to improve the quality of patient care and prevent turnover of staff ${ }^{(3,8)}$. Moreover, there is evidence that the prevalence of anxiety and depressive symptoms has been raised in Greece since 2010 due to European financial crisis and subsequent strict austerity measures ${ }^{(9)}$. Additionally, financial crisis in Greece had a negative effect on working conditions in the health care sector ${ }^{(10)}$,implying an adverse impact on employees' psychological well-being, including oncology nurses. These particular conditions within Greek health care system highlight the particular interest of the present study.

Under this scope, the aim of the present study was to explore among Greek oncology nursing personnel (NP): a) the frequency and intensity of AS, b) the degree of satisfaction from professional interaction, $\mathrm{b}$ ) potential associations between AS severity and satisfaction from professional interaction, and c) potential associations among demographic, vocational, educational factors, AS intensity and satisfaction from professional interaction.

\section{METHOD}

\section{Design}

A descriptive cross sectional and correlational study was applied.

\section{SAMPLE AND SETTING}

The target population was the NP (registered bachelor and assistant nurses) employed in inpatient oncology wards in Athens, Greece. Data collection took place from December 2010 to June 2011 at 2 out of 5 public tertiary oncology hospitals. Each hospital included approximately eight inpatient medical/surgical wards of 20-45 functional beds and 12 to 15 members of NP providing care to adult cancer patients. The reason for including assistant nurses in the present study lies on the fact that in Greece due to nursing shortage, nursing assistants, who receive a two-year nursing education, encompass up to two thirds of total NP, having clinical duties almost identical to those of registered bachelor nurses. Moreover, since international literature suggests an association between nurses' level of education and both quality of collaboration ${ }^{(11)}$, as well as level of mental health ${ }^{(12)}$, both working groups, i.e nurses and assistant nurses, were included in the sample.

Sample size was determined to be up to 60 participants, based on the tables of Cohen to detect a moderate correlation effect, with $80 \%$ statistical power and $\alpha=0.05$ level of statistical significance ${ }^{(13)}$. Due to low response rate in previous surveys concerning Greek Oncology NP, questionnaires were distributed to the entire NP including 115 eligible members of NP working in the aforementioned oncology clinics. The following inclusion criteria were set: a) at least 2-year education in nursing studies, b) a minimum of 6 month work experience in an oncology setting, and c) competence in the use of Greek language. The response rate was $63 \%$ and the final sample consisted of 72 respondents.

Data collection was achieved through a self completed questionnaire pack, which included demographic, educational and vocational data (eg. workload as reflected in the number of patients hospitalized per ward, ranking, length of nursing experience, etc) were included, along with the instruments for the assessment of AS and satisfaction from professional interaction. Each questionnaire was accompanied by a consent form that explained the aim of the study, the voluntary nature of participation, and guaranteed confidentiality and anonymity. The participants were asked to fill in the questionnaire and put it in a no transparent envelope. All sealed envelopes were placed in boxes at each work setting. The researchers visited the work settings after one week in order to remind the members of NP about the survey. All procedures were applied in compliance with the required ethical standards.

\section{Data collection instruments}

The presence of AS was assessed by the modified, Greek-language, 13-item, self- administered version of the Hamilton's Anxiety Scale (HAS) ${ }^{(3)}$. Originally, the HAS was designed to rate the severity of general AS in populations diagnosed with mental health problems under psychotropic medication ${ }^{(14)}$. For that reason, this scale is usually filled in by a clinician after an interview in order to assess the severity of AS However, it has been proven to be suitable after proper modification for self-reporting, in both clinical and non-clinical settings, especially for the assessment of AS in nursing, since health professionals are familiar with the 
implementation of such tools ${ }^{(3)}$. Taking this into consideration, in the modified, self-administered version of the scale the $14^{\text {th }}$ item of the original version which refers to the assessment of the clinician about the overall attitude of the client during the interview is eliminated. Thus, 13 items for the assessment of AS remain in the modified self- administered version. Participants are instructed to respond to the statement Please note the degree to which you experience any of the following:, by choosing one of the five alternative answers, according to the scale range, from 0 to 4 (0: no experience, 4: very intense manifestation) in each of the 13 items included in the scale, reflecting the 13 groups of AS. Thus, 0 denotes absence of AS, whilst 4 indicates very severe AS. The 13 items of the scale, and the subsequent groups of AS, are: anxious mood symptoms, tension symptoms, phobias symptoms, sleep disturbances symptoms, cognitive disturbances symptoms, depressive mood symptoms, musculoskeletal symptoms, sensory symptoms, cardiovascular symptoms, respiratory symptoms, gastrointestinal symptoms, genitourinary and autonomic nervous system's symptoms. A total score, calculated by adding the score assigned to each item represents the overall anxiety level. The overall scale range score is accordingly modified to $0-52$. Scores equal or above 26 are indicative of manifestation of clinical symptoms of anxiety ${ }^{(3)}$. Originally, the construct validity and discriminate validity of the 14 items scale, as well as the inter-rater reliability (correlation coefficient 0.89 ) were reported ${ }^{(14)}$. The metric properties of the Greek-language, modified, 13-item, self-administered version of the scale have been examined and found adequate elsewhere (Cronbach's alpha $\alpha=0.813)^{(3)}$.

The Greek version of the subscale "Satisfaction from Interaction" ("SIS") included in the Index of Work Satisfaction scale (IWS) was used in order to assess the satisfaction from professional interaction. Each subscale of the IWS instrument is considered to be a valid tool, and therefore to be used individually as an instrument ${ }^{(4-5)}$. Furthermore, the translated IWS subscales have been validated in a population of Greek $\mathrm{NP}^{(4)}$. The metric properties of the Greek version of the "SIS" subscale revealed a Cronbach's $\alpha$ internal consistency coefficient of $0.79^{(4)}$. The "SIS" consists of 10 items in total which assess the level of satisfaction from relationships among nurses [5 items- "Satisfaction from Nurse-to- Nurses Interaction" subscale ("SNNIS')], as well as between nurses and physicians [5 items- "Satisfaction from Nurse-to-Physician Interaction" subscale ("SNPIS")], thus including two further subscales, retrospectively. The answers are given in a 7-point Likert scale, and responses range from 1 ('strongly agree") to 7 ("strongly disagree"), thus the total score of the "SIS" ranges from 10 to 70. With regard to the "SNNIS" and "SNPIS", total scores range in both cases from 5 to 35 . The higher the score is, the greater degree of satisfaction is reported.

\section{Statistical analysis}

Data analysis was performed using the Statistical Package for Social Sciences (version 20.00). Descriptive statistics of all variables were explored and mean values and standard deviation (SD) were reported. Normality checks were performed for all variables. In addition, the metric properties of all instruments used were evaluated. Cronbach's alpha internal consistency coefficient and factor analysis with Varimax rotation were performed since both tools were applied for the first time in this population. A total score of AS was calculated by summing the values of the thirteen items of the HAS and used as a continuous variables in order to assess the intensity of AS. Additionally, the overall score of the HAS scale was further transformed in a categorical variable, giving two groups: a) the non-clinical (absence) AS group (HAS total score < 26) and b) the clinical anxiety (presence) symptoms group (HAS total score $\geq 26$ ). This variable was used for the assessment of differences by participants' characteristics. The total level of satisfaction from professional interaction was calculated as the mean of all items of the "SIS" (10 items). The level of satisfaction among members of NP "(SNNIS"- 5 items) was also calculated in the same way, as well as the level of satisfaction from interaction between NP and physicians ("SNPIS" - 5 items). Mean and median values and nonparametric comparisons (Man-Whitney $\mathrm{U}$, Kruskal-Wallis test) were used to assess the differences between groups. In addition, the non parametric correlation coefficient Kendall $\tau$ was calculated where appropriate. The alpha level was set at 0.05 .

\section{RESULTS}

\section{INSTRUMENT'S METRIC PROPERTIES}

Cronbach's alpha of the modified HAS (13 items), "SIS”, "SNNIS", and "SPNIS" was 0.936, 0.717, 0.62 and 0.751, respectively. Exploratory factor analysis of principal components confirmed the construct validity of both scales (HAS, "SIS").

\section{NURSES' DEMOGRAPHIC, EDUCATIONAL AND PROFESSIONAL DATA}

The demographic, educational, and professional characteristics of the participants $(\mathrm{n}=72)$ are presented in Table 1 . Participants' mean age was 34.26 (SD, 7.80) years; their mean work experience in nursing was 121.44 (SD 95.99) months, whereas their work experience in oncology care was 59.65 (SD 57.62) months. The majority of the participants were working on full time (98\%).

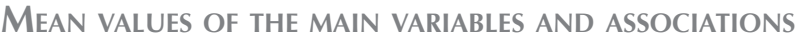
AMONG THEM

\section{ANXIETY SYMPTOMS LEVEL}

The mean cumulative value of the HAS (intensity of AS) was 10.6 [SD: 0.77 , $\min =0$, $\max =45$, Scale Range (SR): $0-52]$. The four most pronounced groups of AS were: i) anxious mood symptoms [Mean: 1.12, SD: 0.07, $\min =0, \max =4$, SR: 0-4], ii) tension symptoms [Mean: 0.19, SD:1.19, $\min =0$, $\max =4$, SR:0-4], iii) sleep disturbances symptoms [Mean:0.14, SD: 1.2, $\min =0$, $\max =4, \mathrm{SR}: 0-4]$ and iv) cognitive disturbances symptoms [Mean:0.89, SD:0.99, $\min =0$, $\max =4, \mathrm{SR}: 0-4] \cdot 11 \cdot 1 \%$ of the respondents reported clinical AS (moderate or above moderate intensity of AS), indicative of total HAS score $\geq 26$ (clinical AS). Table 2 presents the distribution of the intensity of each group of AS according to HAS. 
Table 1 - Demographic, educational and professional characteristics of the participants and statistically significant differences of the percentage of participants in the clinical and non clinical AS groups ( $x^{2}, p$ value) in relation to the aforementioned characteristics Limassol, Cyprus, 2016.

\begin{tabular}{|c|c|c|c|}
\hline Variable & & $\begin{array}{l}\text { Participants' Percentage } \\
\text { (Frequency) }\end{array}$ & $\begin{array}{l}\text { Differences of the percentage of participants in the clinical and } \\
\text { non clinical AS groups }\left(x^{2}, p \text { value }\right)\end{array}$ \\
\hline Gender & $\begin{array}{l}\text { Male } \\
\text { Female }\end{array}$ & $\begin{array}{l}13.9(10) \\
86.1(62)\end{array}$ & $p=0.904$ \\
\hline Family status & $\begin{array}{l}\text { Married } \\
\text { Divorced } \\
\text { Widow } \\
\text { Unmarried }\end{array}$ & $\begin{array}{c}41.7(30) \\
2.8(2) \\
1.4(1) \\
54.2(39)\end{array}$ & $p=0.907$ \\
\hline Having children & $\begin{array}{l}\text { Yes } \\
\text { No }\end{array}$ & $\begin{array}{l}38.9(28) \\
55.6(40)\end{array}$ & $p=0.589$ \\
\hline Education level & $\begin{array}{l}\text { Bachelor Degree } \\
\text { Technological University } \\
\text { Diploma } \\
\text { Master's degree } \\
\text { Nursing specialty }\end{array}$ & $\begin{array}{c}5.6(4) \\
54.2(39) \\
26.4(19) \\
11.1(8) \\
2.8(2)\end{array}$ & $p=0.649$ \\
\hline Shift & $\begin{array}{l}\text { Morning } \\
\text { Rotation }\end{array}$ & $\begin{array}{l}20.8(15) \\
79.2(57)\end{array}$ & $p=0.04$ \\
\hline Ranking & $\begin{array}{l}\text { Nurse assistant } \\
\text { Staff nurse } \\
\text { Under head nurse } \\
\text { Head nurse }\end{array}$ & $\begin{array}{c}27.8(20) \\
56.9(41) \\
11.1(8) \\
4.2(3)\end{array}$ & $p=0.410$ \\
\hline
\end{tabular}

Note: $(\mathrm{n}=72)$

Table 2 - Distribution of the intensity of anxiety symptoms among Greek oncology nursing personnel, according to the HAS instrument - Limassol, Cyprus - 2016.

\begin{tabular}{|c|c|c|c|c|c|}
\hline \multirow{2}{*}{ ANXIETY SYMPTOMS } & \multicolumn{5}{|c|}{ INTENSITY OF SYMPTOMS } \\
\hline & Absence (\%) & Mild (\%) & Moderate $(\%)$ & Severe $(\%)$ & Very severe $(\%)$ \\
\hline Tension symptoms & 41.7 & 25.0 & 15.3 & 11.1 & 6.9 \\
\hline Anxious mood symptoms & 38.9 & 25 & 22.2 & 12.5 & 1.4 \\
\hline Phobias symptoms & 75.0 & 16.7 & 5.6 & 1.4 & 1.4 \\
\hline Sleep disturbances symptoms & 38.9 & 34.7 & 9.7 & 6.9 & 9.7 \\
\hline Cognitive disturbances symptoms & 44.2 & 31.9 & 18.1 & 1.4 & 4.2 \\
\hline Depressive mood symptoms & 58.3 & 15.3 & 12.5 & 9.7 & 4.2 \\
\hline Muscular-skeletal symptoms & 59.7 & 18.1 & 8.3 & 5.6 & 8.3 \\
\hline Sensory symptoms & 63.9 & 23.6 & 2.8 & 5.6 & 4.2 \\
\hline Cardiovascular symptoms & 54.2 & 22.2 & 11.1 & 8.3 & 4.2 \\
\hline Respiratory symptoms & 66.7 & 18.1 & 8.3 & 4.2 & 2.8 \\
\hline Gastro- intestinal symptoms & 68.1 & 11.1 & 13.9 & 2.8 & 4.2 \\
\hline Genitor- urinary symptoms & 72.1 & 13.9 & 8.3 & 5.6 & 0.0 \\
\hline Autonomic symptoms & 62.5 & 25.0 & 4.2 & 5.6 & 2.8 \\
\hline
\end{tabular}

Note: $(n=72)$

\section{ASSOCIATIONS BETWEEN ANXIETY SYMPTOMS AND DEMOGRAPHIC/EDUCATIONAL/VOCATIONAL VARIABLES}

No statistically significant differences were observed in the intensity of AS (HAS overall score) and personal/educational/vocational variables, with the exception of the type of working shift (Mann-Whitney U, p=0.031).

In relation to the intensity of anxiety symptoms groups, statistically significant weak positive correlations were found between the number of beds and presence of both anxious mood symptoms (tau=0.0201, $\mathrm{p}=0.040$ ) and tension symptoms ( $\operatorname{tau}=0.213, \mathrm{p}=0.030)$. Moreover, work experience in nursing was associated with autonomic symptoms (tau=0.262, $\mathrm{p}=0.006$ ), as well as work experience as oncology nurse $(\operatorname{tau}=0.213, \mathrm{p}=0.026)$. The age of the participants was statistically significantly associated with respiratory symptoms ( $\operatorname{tau}=.187, \mathrm{p}=0.05)$, genitor-urinary symptoms (tau=0.212, $\mathrm{p}=0.027)$, and autonomic nervous Osystem symptoms (tau=0.291, $\mathrm{p}=0.002)$.

\section{SATISFACTION FROM PROFESSIONAL INTERACTION DEGREE}

The mean score of "SIS', was $4.52(\mathrm{SD}, 0.8)$ which is only moderate on a theoretical range of 1-7 of the scale. In terms of the subscales, "SNNIS" mean score was 5.10(SD, 1.04) and "SPNIS" was 4.21(SD, 0.77).

\section{ASSOCIATIONS BETWEEN SATISFACTION FROM INTERACTION} AND DEMOGRAPHIC/ EDUCATIONAL/ VOCATIONAL VARIABLES

Female NP reported higher satisfaction from interaction among them (Mann-Whitney U, p=0.009) than males. No 
further statistically significant differences in the degree of satisfaction from interaction, either nurse to nurse or nurse to physician, were noted with regard to educational, vocational, or family status parameters. A statistically significant negative weak association between age and "SNNI" (tau=-0.234, $\mathrm{p}=0.006$ ), as well as "SPNI" (tau=-215, p=0.010) was observed. There was no statistically significant association between SIS and number of beds, or work experience as oncology nurse.

\section{ASSOCIATION BETWEEN THE PRESENCE OF CLINICAL AS AND SATISFACTION FROM PROFESSIONAL INTERACTION}

Participants who reported clinical AS were less satisfied from the quality of interaction (Table 3 ). The observed differences were statistically significant in terms of both the overall scale "SIS" (Mann-Whitney U, p=0.005) and the subscales "SNNIS" (Mann-Whitney U, p=0.014) and "SPNIS" (Mann-Whitney U, p= 0.013).

\section{ASSOCIATION BETWEEN GROUPS OF ANXIETY SYMPTOMS AND SATISFACTION FROM INTERACTION}

Statistically significant negative mildly to moderate associations were noted between the majority of groups of AS and "SIS", as well as "SNNIS" and "SPNIS". These associations are presented in Table 4.

Table 3 - Mean values of satisfaction from professional interpersonal relationships and presence of clinical anxiety symptoms - Limassol, Cyprus, 2016.

\begin{tabular}{|c|c|c|c|}
\hline \multirow{3}{*}{ VARIABLE } & \multicolumn{3}{|c|}{ CLINICAL ANXIETY SYMPTOMS } \\
\hline & \multirow{2}{*}{$\begin{array}{l}\text { PRESENCE } \\
\text { Mean (SD) }\end{array}$} & \multicolumn{2}{|c|}{ ABSENCE } \\
\hline & & Mean (SD) & $p$ value \\
\hline Satisfaction from professional interaction among nursing personnel & $4.21( \pm 0.74)$ & $5.21( \pm 1.0)$ & 0.014 \\
\hline $\begin{array}{l}\text { Satisfaction from professional interaction between nursing personnel and } \\
\text { physicians }\end{array}$ & $3.55( \pm 0.74)$ & $4.30( \pm 0.73)$ & 0.013 \\
\hline $\begin{array}{l}\text { Nursing personnel's total professional satisfaction from interaction both among } \\
\text { them and physicians. }\end{array}$ & $3.76( \pm 0.53)$ & $4.62( \pm 0.86)$ & 0.005 \\
\hline
\end{tabular}

Abbreviations: SD - Standard Deviation

Note: $(\mathrm{n}=72)$

Table 4 - Association between groups of anxiety symptoms and a) SIS, b) SNNIS, c) SPNIS - Limassol, Cyprus, 2016.

\section{GROUP OF ANXIETY SYMPTOMS}

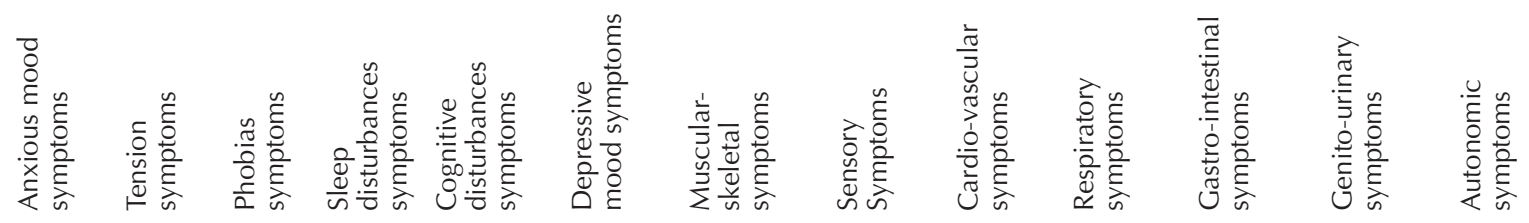

\begin{tabular}{|c|c|c|c|c|c|c|c|c|c|c|c|c|c|}
\hline \multicolumn{14}{|c|}{ VARIABLES } \\
\hline SIS & $\begin{array}{l}\tau=-0.16 \\
p=0.07\end{array}$ & $\begin{array}{l}\tau=-0.20 \\
p=0.02\end{array}$ & $\begin{array}{l}\tau=-0.16 \\
p=0.07\end{array}$ & $\begin{array}{l}\tau=-0.23 \\
p=0.01\end{array}$ & $\begin{array}{l}\tau=-0.17 \\
p=0.06\end{array}$ & $\begin{array}{c}\tau=-0.33 \\
\mathbf{p}<0.0001\end{array}$ & $\begin{array}{c}\tau=-\mathbf{0 . 2 5} \\
\mathbf{p}=\mathbf{0 . 0 0 7}\end{array}$ & $\begin{array}{c}\tau=-0.33 \\
\mathbf{p}<0.0001\end{array}$ & $\begin{array}{l}\tau=-\mathbf{0 . 2 3} \\
\mathbf{p}=\mathbf{0 . 0 1}\end{array}$ & $\begin{array}{l}\tau=-0.23 \\
\mathbf{p}=0.02\end{array}$ & $\begin{array}{c}\tau=-\mathbf{0 . 2 5} \\
\mathbf{p}=\mathbf{0 . 0 0 8}\end{array}$ & $\begin{array}{l}\tau=-\mathbf{0 . 3 5} \\
\mathbf{p}<0.0001\end{array}$ & $\begin{array}{l}\tau=-0.32 \\
p=0.001\end{array}$ \\
\hline SNNIS & $\begin{array}{l}\tau=-0.16 \\
p=0.08\end{array}$ & $\begin{aligned} \tau=-0.23 \\
p=0.01\end{aligned}$ & $\begin{array}{l}\tau=-0.16 \\
p=0.09\end{array}$ & $\begin{array}{l}\tau=-0.21 \\
p=0.02\end{array}$ & $\begin{array}{l}\tau=-0.03 \\
p=0.75\end{array}$ & $\begin{array}{c}\tau=-0.25 \\
p=0.009\end{array}$ & $\begin{array}{l}\tau=-0.18 \\
p=0.05\end{array}$ & $\begin{array}{l}\tau=-\mathbf{0 . 2 6} \\
\mathbf{p}=\mathbf{0 . 0 0 7}\end{array}$ & $\begin{array}{l}\tau=-0.22 \\
p=0.02\end{array}$ & $\begin{array}{c}\tau=-\mathbf{0 2 6} \\
\mathbf{p}=\mathbf{0 . 0 0 7}\end{array}$ & $\begin{array}{l}\tau=-0.24 \\
p=0.01\end{array}$ & $\begin{array}{l}\tau=-0.27 \\
p=0.006\end{array}$ & $\begin{array}{l}\tau=-0.30 \\
\mathbf{p}=0.001\end{array}$ \\
\hline SPNIS & $\begin{array}{l}\tau=-0.19 \\
p=0.03\end{array}$ & $\begin{array}{l}\tau=-0.16 \\
p=0.08\end{array}$ & $\begin{array}{l}\tau=-0.18 \\
p=0.05\end{array}$ & $\begin{array}{l}\tau=-0.18 \\
p=0.05\end{array}$ & $\begin{array}{l}\tau=-0.23 \\
p=0.01\end{array}$ & $\begin{array}{c}\tau=-0.33 \\
p<0.0001\end{array}$ & $\begin{array}{c}\tau=-0.30 \\
p=0.0001\end{array}$ & $\begin{array}{c}\tau=-0.35 \\
p<0.0001\end{array}$ & $\begin{array}{l}\tau=-0.22 \\
p=0.02\end{array}$ & $\begin{array}{l}\tau=-0.16 \\
p=0.09\end{array}$ & $\begin{array}{c}\tau=-0.2 \\
p=0.03\end{array}$ & $\begin{array}{l}\tau=-0.32 \\
p=0.001\end{array}$ & $\begin{array}{l}\tau=-0.22 \\
p=0.02\end{array}$ \\
\hline
\end{tabular}

\section{DISCUSSION}

This is the first study to our knowledge that provides evidence on the association between self-reported severity of symptoms of mental health problems and perceived quality of professional interaction among employees in oncology settings, as well as workload variables. Within this framework, the main findings were: a) the prevalence of AS of moderate or above intensity hovered more than $10 \%$; b) moderate satisfaction from professional interaction was reported among NP, as well as from relationships with physicians; c) Anxiety symptoms in NP were associated with feelings about the quality of professional relationships; and d) workload was associated with the presence of AS. In fact, associations herein were shown in relation to the intensity of AS, as well as across the groups of clinical and non clinical AS.

It should be noted that the instrument applied in the present study assesses general AS, without focusing on any particular diagnosis; such symptoms may be reported as part of anxiety, mood or somatic disorders ${ }^{(2,14)}$. Thus, this study provides evidence on the severity of general anxiety symptoms and not on any particular psychiatric disorder. Moreover, based on the cross-sectional design of the present study, we report data regarding a particular point of time, not a life-long prevalence. Thus, comparison with prevalence of AS from general population is inappropriate. It would be more suitable to compare the present findings with data from international literature focused on NP, and especially oncology health professionals. Unfortunately, there is remarkably scant data regarding the prevalence of psychiatric morbidity in cancer nurses ${ }^{(7)}$. To our knowledge this is the first study in which the occurrence of general AS was assessed in oncology NP, along with its association with job satisfaction related variables. The majority of relevant studies are focused either on other nursing specialties ${ }^{(4)}$ or 
different variables, such as compassion fatigue ${ }^{(15)}$, burnout $^{(8)}$ or death anxiety ${ }^{(7)}$.

Compared to other nursing specialties, a study among Greek Critical Care nurses revealed that approximately 25\% of them reported clinical $\mathrm{AS}^{(4)}$, whilst a study in a sample of 1437 hospital nurses in China showed that almost one out of two employees states clinical $\mathrm{AS}^{(16)}$, which was also supported by a study in Iranian hospital nurses ${ }^{(17)}$. Moderate degree of AS within workplace was also reported in paediatric intensive care nurses ${ }^{(6)}$. Differences in the social and work environment in terms of culture and education may explain the discrepancies among the aforementioned data, as well as differences in the populations studied, response rates and instruments for the assessment of AS used.

The weak positive association reported herein between AS and work experience was also noted in a study among hospital nurses in Norway ${ }^{(18)}$. However, higher levels of AS levels in younger nurses have been reported elsewhere ${ }^{(19)}$, which may indicates shorter work experience. Moreover, it has been showed that death anxiety symptoms in nurses, including oncology nurses, is more frequent in younger, less experienced nurses ${ }^{(7)}$.

With regard to work-related variables, data show a positive association between degree of AS and working fulltime, as well as lack of postgraduate qualification ${ }^{(19)}$. In the present study there was no association between the severity of AS and education or work pattern, with the exception of the type of working shift, since nurses following rotation program reported presence of AS compared to those in the morning shift. Moreover, a positive relationship between the degree of AS and workload as it is reflected by the number of beds in the working ward was noted herein for the first time in the literature. Previous studies have investigated numerous work- related variables, such as number of night shifts ${ }^{(18)}$, time between working shifts ${ }^{(20)}$ or effort- reward imbalance ${ }^{(16)}$, however none of them has included any workload related variable.

In relation to the observed association between the degree of AS and satisfaction from interaction, there are data which support this relationship between nurses' mental health problems and professional satisfaction variables ${ }^{(4,21)}$. However, none of these studies focuses on oncology nurses. Overall, the present results suggest a role of the quality of professional interaction in nurses' symptoms of mental health problems, and vice versa, thus indicating the need for targeted interventions towards both variables. International literature suggests that positive and harmonious relationships with colleagues, together with the ability to share problems with other team members are crucial factors not only in keeping nurses' experienced stress at low levels, but also in promoting their professional satisfaction ${ }^{(22)}$. In particular, a study in a sample of 77 oncology Brazilian nurses, supported that poor quality of nurse-to-nurse interaction might be a stressful factor ${ }^{(23)}$. Moreover, other data show that the quality of communication between nurses and physicians might be a factor related not only to nurses' perceived level of professional satisfaction but occupational stress, as well ${ }^{(24)}$.
With regard to the satisfaction related to the quality of interaction among oncology health professionals, our respondents reported moderate levels, as well as higher satisfaction from the relationships among them, compared to the relationship with physicians. This difference might be attributed to the fact that in Greece a physician-oriented culture still exists, and often physicians look down on nurses and most importantly on nursing assistants ${ }^{(25)}$. In contrast, a study in Canada revealed that both nurses and physicians rate relatively highly the quality of interaction among them, including the degree of supportive relationships and the quality of communication ${ }^{(26)}$. This difference may be related to the professional status of Canadian oncology nurses or to other cultural factors related to the educational or health care system, such as autonomy issues, which have been found to influence the quality of collaboration among health care professionals ${ }^{(22)}$. In Greece, there is still lack of advanced nursing clinical roles, resulting in diminished autonomy and probably low professional status ${ }^{(27)}$. Indeed, it has been shown that advanced clinical nurses tend to regard the quality of collaboration with physicians as being high ${ }^{(28)}$.

There were a number of limitations in the present study. The cross-sectional nature of the study cannot imply causality between the manifestation of AS and the degree of satisfaction from professional interaction. In fact, other important factors, irrelevant to dysfunctional relationships in the work environment, such as everyday life tension or genetic predisposition, may be linked to AS, as well, however not reported here. As far as the intensity of AS is concerned, future studies that apply instruments able to distinguish between the state and trait components of anxiety could provide better insight into the correlates of nurses' mental health problems and personality characteristics ${ }^{(6)}$. Similarly, instruments targeted at specific psychiatric diagnoses might also give more accurate information on oncology nurses' mental health problems ${ }^{(2)}$. Finally, individuals who suffer from severe degree of psychiatric symptoms may be more reluctant to participate in such studies $^{(2)}$. In any case, the extent to which non participation has affected study results is not known.

Future mixed methods studies are proposed investigating work related anxiety sources among oncology nurses and types of effective copying strategies. Moreover, it would be interesting to explore the way nurse-physician relations associate with the quality of delivered care and nurses' mental health problems. Additionally, there is need for longitudinal interventional studies aiming either in promoting communication and collaboration between nurses and physicians ${ }^{(22)}$ or alleviating the severity of symptoms of mental health problems ${ }^{(6-7)}$, since both variables have been shown to be associated with the quality of delivered care ${ }^{(29)}$. Finally, routine screening for symptoms of psychological distress and referrals for counseling and support might represent suitable interventions to prevent deterioration of AS in oncology nurses ${ }^{(8)}$.

\section{CONCLUSION}

Approximately one out of ten Greek hospital oncology NP reports clinical AS. The presence of AS is associated 
with the perceived quality of professional interaction among them, as well as with physician. Moreover, Greek oncology NP seems to be moderately satisfied from the quality of professional interaction with their peers and physicians. Further qualitative research is needed to identify work- related factors to oncology nurses' mental health problems.

\section{RESUMO}

Objetivo: Explorar a gravidade dos Sintomas de Ansiedade (SA) entre equipes de enfermagem Gregas, o grau de satisfação nas relações profissionais e a potencial associação entre estes indicadores. Método: Estudo transversal e correlacional realizado em dois hospitais oncológicos Gregos, abrangendo 72 membros das equipes de enfermagem. A escala de ansiedade Hamilton foi utilizada para a avaliação da severidade dos Sintomas de Ansiedade, assim como a subescala do índice de Satisfação no Trabalho "Satisfação da Interação" para o grau de satisfação resultante das relações profissionais entre o pessoal de enfermagem (PE) e entre o pessoal de enfermagem e médicos (EM). Resultados: 11\% da amostra revela SA clínicos [ $\geq 26$, escala: 0-52]. Satisfação da interação profissional entre o PE [5.10 (SD: 1.04), SR: 1-7] e EM [4.21 (SD: 0.77), SR: 1-7], demonstrando que foi moderada em ambos os grupos. Significativas associações estatísticas foram observadas entre Sintomas de Ansiedade clínicos e a satisfação de interação profissional entre pessoal de enfermagem $(p=0.014)$ e EM ( $p=0.013)$. Conclusão: Ações para a redução da ansiedade e melhora das relações profissionais são essenciais de forma a reduzir o stress psicológico nas equipas de enfermagem em oncologia.

\section{DESCRITORES}

Ansiedade; Enfermagem Oncológica; Depressão; Relações Interprofissionais; Satisfação no Trabalho; Saúde do Trabalhador.

\section{RESUMEN}

Objetivo: Explorar la gravedad de los Síntomas de Ansiedad (SA) entre los equipos de la enfermería oncológica Griega, el grado de satisfacción en las relaciones laborales y la potencial asociación entre estos indicadores. Método: Estudio transversal y correlacional, se realizó en dos hospitales de Oncología Griegos, en 72 miembros de los equipos de enfermería. Fue utilizada la Escala de Ansiedad de Hamilton para la evaluación de la gravedad de SA y también la subescala del índice de Satisfacción en el Trabajo "Satisfacción de Interacción" para evaluar el grado de satisfacción de las relaciones laborales entre el personal de enfermería (PE) y entre el personal de la enfermería y los médicos (EM). Resultados: $11 \%$ de la muestra informó SA clínicos [ $\geq 26$, escala: 0-52]. La satisfacción de la interacción profesional entre el PE [5.10 (SD: 1.04), SR: 1-7] y el EM [4.21 (SD: 0.77), SR: 1-7] fue moderada en ambos grupos. Significativas asociaciones estadísticas fueron notadas entre los SA clínicos y la satisfacción de la interacción profesional entre el PE $(\mathrm{p}=0.014)$ y el EM ( $\mathrm{p}=0.013)$. Conclusión: Las técnicas de reducción de la ansiedad y del mejoramiento entre las relaciones laborales, son extremadamente importantes, con el fin de reducir el estrés psicológico en los equipos de enfermería de oncología.

\section{DESCRIPTORES}

Ansiedad; Enfermería Oncológica; Depresión; Relaciones Interprofesionales; Satisfacción en el Trabajo; Salud Laboral.

\section{REFERENCES}

1. Taghinejad H, Suhrabi Z, Kikhavani S, Jaafarpour M, Azadi A. Occupational mental health: a study of work-related mental health among clinical nurses. J Clin Diagn Res. 2014;8(9):WC01-3.

2. Sadock B, Sadock V. Kaplan and Sadock's pocket handbook of clinical psychiatry. Fifth ed. Philadelphia: Lippincott Williams and Wilkins; 2010.

3. Stathopoulou H, Karanikola MNK, Panagiotopoulou F, Papathanassoglou EDE. Anxiety levels and related symptoms in emergency nursing personnel in Greece. J Emerg Nurs. 2011;37(4):314-20.

4. Karanikola MNK, Papathanassoglou EDE, Kalafati M, Stathopoulou H. Exploration of the association between professional interactions and emotional distress of intensive care unit nursing personnel. Dimens Crit Care Nurs. 2012;31(1):37-45.

5. Stamps PL. Nurses and work satisfaction: an index for measurement. Am J Nurs. 1998;98(3):16KK-16LL.

6. Polat S, Alemdar DK, Gürol A. Paediatric nurses' experience with death: the effect of empathic tendency on their anxiety levels. Int J Nurs Pract. 2013;19(1):8-13.

7. Peters L, Cant R, Payne S, O'Connor M, McDermott F, Hood K, et al. How death anxiety impacts nurses' caring for patients at the end of life: a review of literature. Open Nurs J. 2013;7:14-21.

8. Hecktman H. Stress in pediatric oncology nurses. J Pediatr Oncol Nurs. 2012;29(6): 356-61.

9. Economou M, Madianos M, Peppou LE, Souliotis K, Patelakis A, Stefanis C. Cognitive social capital and mental illness during economic crisis: A nationwide population-based study in Greece. Soc Sci Med. 2014;100:141-7.

10. Simou E, Koutsogeorgou E. Effects of the economic crisis on health and healthcare in Greece in the literature from 2009 to 2013: a systematic review. Health Policy. 2014; 115(2-3):111-9.

11. Polansky M. The advanced practice professionals' perspective: keys to a good working relationship between advanced practice professions and physicians. Am Soc Clin Oncol Educ Book. 2013. doi: 10.1200/EdBook_AM.2013.33.e375

12. Fothergill A, Edwards D, Hannigan B, Burnard P, Coyle D. Self-esteem in community mental health nurses: findings from the all-Wales stress study. J Psychiatr Ment Health Nurs. 2000;7(4):315-21.

13. Burns N, Grove SK. Practice of nursing research. $4^{\text {th }}$ ed. Philadelphia: Saunders; 2001. 
14. Hamilton M. Hamilton Anxiety Scale (HAMA). In: Guy W, editor. ECDEU assessment manual for psychopharmacology, US National Institute of Health. Rockville: Psychopharmacology Research Branch; 1976.

15. Isikhan V, Comez T, Danis MZ. Job stress and coping strategies in health care professionals working with cancer patients. Eur J Oncol Nurs. 2004;8(3):234-44.

16. Gao YQ, Pan BC, Sun W, Wu H, Wang JN, Wang L. Anxiety symptoms among Chinese nurses and the associated factors: a cross sectional study. BMC Psychiatry. 2012;12:14.

17. Kayalha H, Yazdi Z, Rastak S, Dizaniha M. Obvious and hidden anxiety and the related factors in operating room nurses employed in general hospital, Qazvin, Iran: a cross-sectional study. Glob J Health Sci. 2013;5(6):202-8.

18. Øyane NMF, Pallesen S, Moen BE, Akerstedt T, Bjorvatn B. Associations between night work and anxiety, depression, insomnia, sleepiness and fatigue in a sample of Norwegian nurses. PLoS One. 2013;8(8):e70228.

19. Hegney DG, Craigie M, Hemsworth D, Osseiran-Moisson R, Aoun S, Francis K, et al. Compassion satisfaction, compassion fatigue, anxiety, depression and stress in registered nurses in Australia: study 1 results. J Nurs Manag. 2014;22(4):506-18.

20. Eldevik MF, Flo E, Moen BE, Pallesen S, Bjorvatn B. Insomnia, excessive sleepiness, excessive fatigue, anxiety, depression and shift work disorder in nurses having less than 11 hours in-between shifts. PLoS One. 2013;8(8):e70882.

21. Arafa MA, Nazel MWA, Ibrahim NK, Attia A. Predictors of psychological well-being of nurses in Alexandria, Egypt. Int J Nurs Pract. 2003;9(5):313-20.

22. Papathanassoglou EDE, Karanikola MNK, Kalafati M, Giannakopoulou M, Lemonidou C, Albarran JW. Professional autonomy, collaboration with physicians, and moral distress among European intensive care nurses. Am J Crit Care. 2012; 21(2):e41-52.

23. Rodrigues A, Chaves E. Stressing factors and coping strategies used by oncology nurses. Rev Latino Am Enfermagem. 2008;16(1):24-8.

24. Borteyrou X, Truchot D, Rascle N. Development and validation of the Work Stressor Inventory for Nurses in Oncology: preliminary findings. J Adv Nurs. 2014;70(2):443-53.

25. Patiraki-Kourbani E. Greece (Hellenic Republic). In: D’Avanzo CE, Geissler EM. Cultural Health Assessment ; 2003. p. 303-7.

26. Lee CT, Doran DM, Tourangeau AE, Fleshner NE. Perceived quality of interprofessional interactions between physicians and nurses in oncology outpatient clinics. Eur J Oncol Nurs. 2014;18(6):619-25.

27. Papathanassoglou EDE, Tseroni M, Karydaki A, Vazaiou G, Kassikou J, Lavdaniti M. Practice and clinical decision-making autonomy among Hellenic critical care nurses. J Nurs Manag. 2005;13(2):154-64.

28. Maylone MM, Ranieri L, Quinn Griffin MT, McNulty R, Fitzpatrick JJ. Collaboration and autonomy: perceptions among nurse practitioners. J Am Acad Nurse Pract. 2011; 23(1):51-7.

29. Aiken LH, Clarke SP, Sloane DM. Hospital staffing, organization, and quality of care: cross-national findings. Int J Qual Health Care. 2002;14(1):5-13.

Financial support: This study has been partially funded by the Cyprus University of Technology, (internal funding) as part of the project "Primary Prevention and Mental Health Care in the Community". 